\title{
Synthesis of High-Density Vertically Aligned Carbon Nanotubes Using Ultrasonic Nebulizer
}

\author{
Jianhui Zhang ${ }^{1,2}$, Wei $\mathrm{Li}^{1,3}$, Tetsuo Soga ${ }^{4}$, Takashi Jimbo ${ }^{4}$, Takayoshi Tanji ${ }^{1,2}$ \\ ${ }^{1}$ EcoTopia Science Institute, Nagoya University, Nagoya, Japan; ${ }^{2}$ Global Research Center for Environment and Energy Based on \\ Nanomaterials Science, Nagoya, Japan; ${ }^{3}$ Graduate School of Engineering, Nagoya University, Nagoya, Japan; ${ }^{4}$ Department of Fron- \\ tier Materials, Nagoya Institute of Technology, Nagoya, Japan. \\ Email: zhangjianhuijp@yahoo.co.jp
}

Received October $17^{\text {th }}, 2011$; revised December $27^{\text {th }}, 2011$; accepted February $22^{\text {nd }}, 2012$

\begin{abstract}
Vertically aligned carbon nanotubes (VACNTs) array with high density have been synthesized from a mixture of ferrocene and ethanol using ultrasonic nebulizer techniques. Using scanning electron microscopy (SEM) and transmission electron microscopy (TEM) as well as Raman spectroscopy, investigations reveal that the vertically aligned CNTs are multi-wall CNTs with well-ordered graphene sheets and are about $20-50 \mathrm{~nm}$ in diameter. We found that high density vertically aligned CNTs can be synthesized at $750^{\circ} \mathrm{C}-850^{\circ} \mathrm{C}$ and that the length and density of vertically aligned CNTs increase with increasing growth temperatures. In addition, the single-walls CNTs have well-ordered graphene sheet and are about $2 \mathrm{~nm}$ in diameter on silicon substrates at $650^{\circ} \mathrm{C}$.
\end{abstract}

Keywords: Carbon Nanotubes; Chemical Vapor Deposition; Transmission Electron Microscope

\section{Introduction}

Since the discovery of carbon nanotubes (CNTs) [1] attempts have been extensively explored to take advantage of their unique properties for specific applications due to their unique morphological characteristics [2]. Potential technical applications in the area of electronic devices [3] and electron field emissions [4] have been proposed or explored. To understand their intrinsic properties, it is necessary to produce highly oriented CNTs [5]. Vertically aligned CNTs can be produced using various chemical vapor deposition (CVD) methods, such as the hot filament CVD [6], plasma enhanced CVD [7] and thermal CVD [8]. Among these synthesis methods, the thermal CVD has been widely used, as it provides a way for large area synthesis of vertically aligned CNTs for electron emitters. In many cases, the spray pyrolysis CVD method has been successfully applied in making CNTs for many years [9]. It is also an important method for the synthesis of vertically aligned CNTs and considerable progress has been achieved [10]. By this method of CVD, the high density oriented CNTs generally need pre-patterned metal catalysts substrate, and a carbon source gas is introduced into the quartz tube. The high density oriented CNTs are grown on this catalyst-coated substrate using a pyrolysis of the carbon source gas.

In this study, we demonstrate the synthesis of high density oriented CNTs using the ultrasonic nebulizer
CVD technique on Si substrate under atmospheric pressure. In this method, the pre-processing of substrate is not necessary and the purity of the CNTs is high. The produced vertically aligned CNTs are multi-walled and exhibit crystallization.

\section{Experiment}

Figure 1 shows the schematic diagram of the CVD apparatus. The ultrasonic nebulizer is connected to a quartz tube and a $\mathrm{N}_{2}$ gas cylinder. Si (100) substrates of size 10 $\mathrm{mm} \times 10 \mathrm{~mm}$ were cleaned in acetone and methanol using an ultrasonicator then in de-ionized water and finally dried using a nitrogen blower. The substrates were kept in a quartz boat, which was then placed in the center of the quartz reaction tube. One side of the quartz tube was connected to an ultrasonic nebulizer. The ferrocene and ethanol was used as a catalyst and as carbons source, respectively. Before flowing the ferrocene/ethanol ( $0.1 \mathrm{~g} /$ $100 \mathrm{ml}$ ) mixture to the quartz tube, the electric furnace should reach to the desired temperature. When the electric furnace was heated up to the desired temperature the ultrasonic nebulizer was switched on. The ferrocene/ ethanol mixture was changed to a thin mist. The flow of $\mathrm{N}_{2}$ was maintained to pass this mist inside the electric furnace. After the deposition the furnace was switched off and allowed to cool down to a temperature below $100^{\circ} \mathrm{C}$. Through this method, the ultrasonic nebulizer $(1.65 \mathrm{MHz}$, 


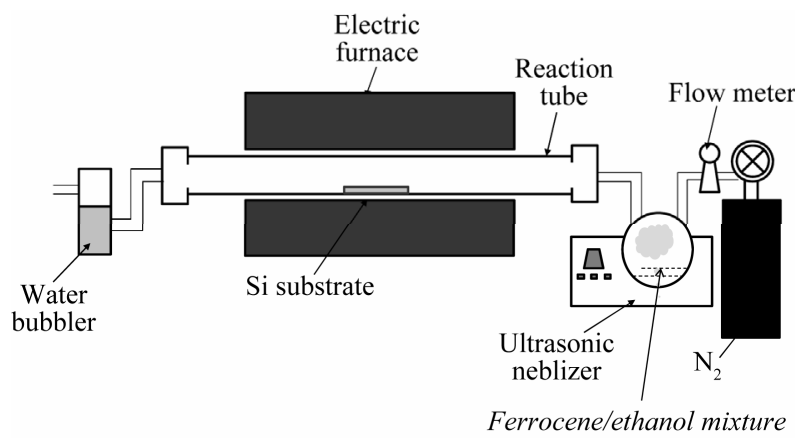

Figure 1. Schematic image of the apparatus of the CVD.

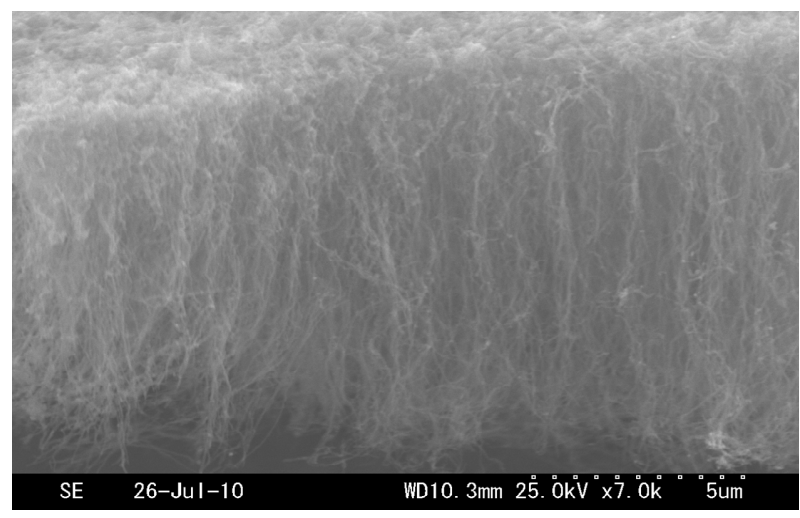

Figure 2. SEM image of CNTs on silicon substrate synthesized at $750^{\circ} \mathrm{C}$.

Atom Medical Corp Model 303) produced a mist of ferrocene/ethanol. Finally, produced samples were analyzed using a scanning electron microscope (SEM, Hitachi S$3000 \mathrm{H}$ ), a transmission electron microscope (TEM, JEOL JEM-3010 EXII) and a Raman spectroscope (JASCO, NRS-1500W). The excitation wavelength for the Raman measurements was $532 \mathrm{~nm}$.

\section{Results and Discussions}

The ultrasonic nebulizer experiment was carried out in a temperature range between $650^{\circ} \mathrm{C}$ to $950^{\circ} \mathrm{C}$. The dense and vertically aligned CNTs were observed by SEM on the substrate as shown in Figure 2. The diameter and length of the CNTs were about $50 \mathrm{~nm}$ and a ten several microns, respectively.

Short and thin CNTs film was observed in the sample synthesized at $650^{\circ} \mathrm{C}$ as show in Figure 3(a). Straight and vertically aligned CNTs mat were observed in the sample synthesized at $750^{\circ} \mathrm{C}-850^{\circ} \mathrm{C}$ as shown in Figures 3(b) and (c). We can be observed the density of vertically aligned synthesized at $750^{\circ} \mathrm{C}-850^{\circ} \mathrm{C}$, and we hope that this kind of straight CNTs should be promising for various field emission electron source applications. However, we focused on the morphology of the CNTs synthesized at $950^{\circ} \mathrm{C}$. We only observed kinked CNTs as products in this deposition as shown in Figure 3(d), the

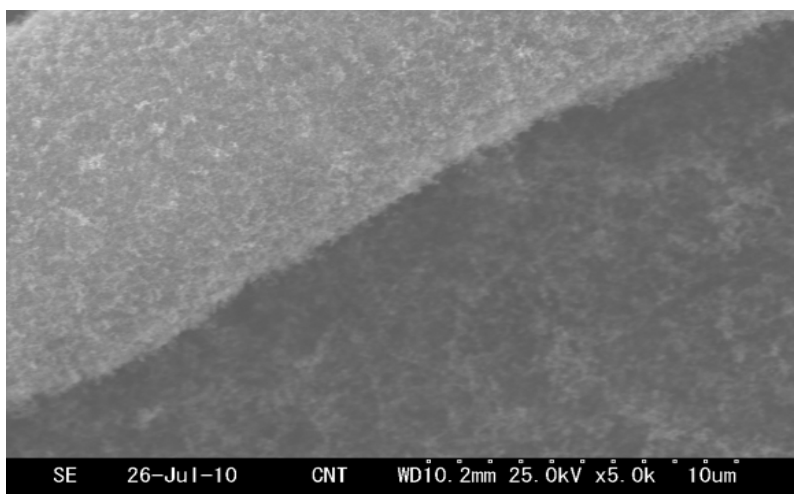

(a)

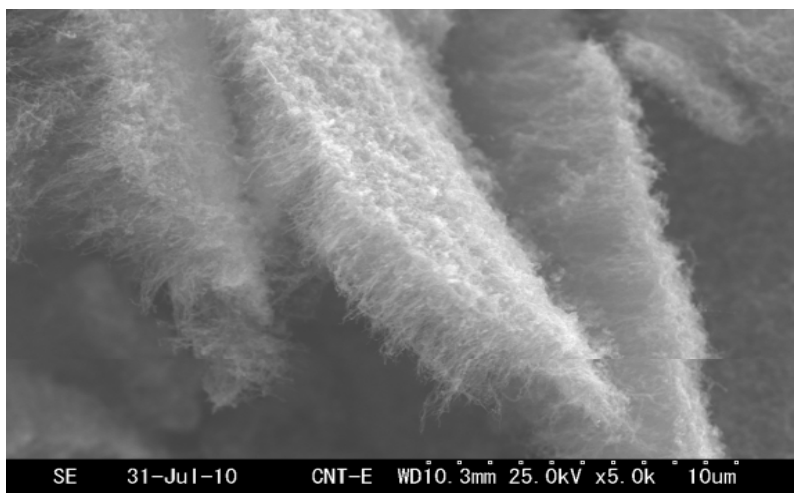

(b)

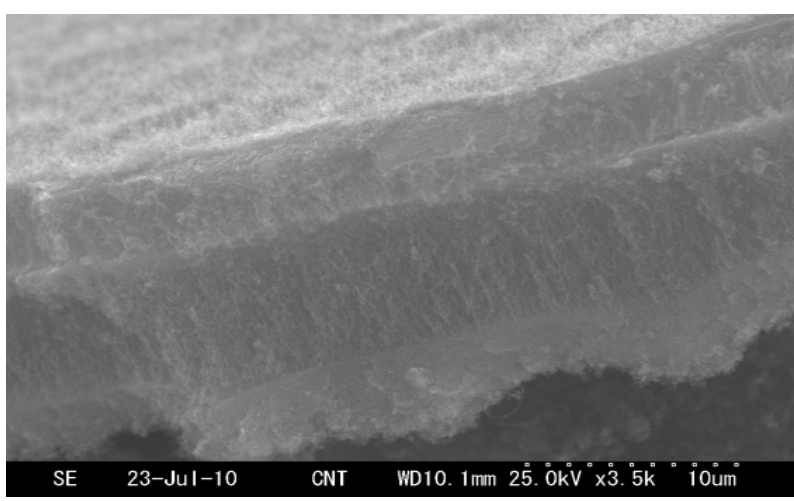

(c)

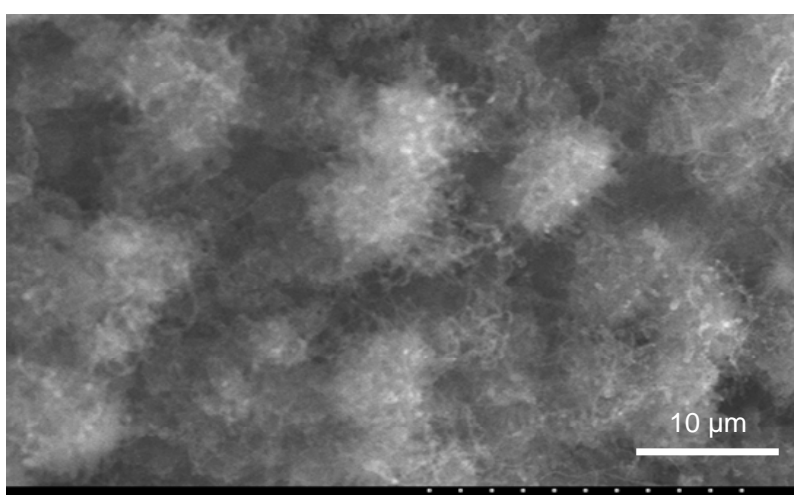

(d)

Figure 3. SEM images of CNTs on silicon substrate synthesized at: (a) $650^{\circ} \mathrm{C}$; (b) $750^{\circ} \mathrm{C}$; (c) $850^{\circ} \mathrm{C}$ and (d) $950^{\circ} \mathrm{C}$. 
vertically aligned CNTs obviously could not be synthesized at this temperature.

A TEM observation was performed on the synthesized CNTs at $650^{\circ} \mathrm{C}-950^{\circ} \mathrm{C}$. Single-walled CNTs (SWNTs) can be observed in this sample as shown in Figure 4(a). The diameter of SWNTs were $2-4 \mathrm{~nm}$. As shown in Figures 4(b) and (c), it can be clearly observed that the CNTs have straight morphologies, smooth walls, close end and clean surfaces. The CNTs have a multi-walled structure with a hollow inside the CNTs. The outer diameters of the CNTs are within a range of $10-30 \mathrm{~nm}$. The inner diameter of the CNTs was typically about 2 - 5 $\mathrm{nm}$. And the kinked CNTs and aggregation of carbon particles were observed at $950^{\circ} \mathrm{C}$ as shown in Figure 4(d).

Figure 5 shows an EDS spectrum with four strong peaks, which represent carbon, copper, silicon, and Fe. This indicates that the growth of VACNTs originated from $\mathrm{Fe}$ or $\mathrm{Fe}$ carbide particles on the silicon substrate. The $\mathrm{Cu}$ peak results from a $\mathrm{Cu}$ grid.

Figure 6 demonstrates the thermo-gravimetric analysis (TGA) result of the products, weight starts to reduce from near $465^{\circ} \mathrm{C}$, the CNTs completely evaporate above $725^{\circ} \mathrm{C}$, while the weight loss of purified CNTs by burn off starts from $550^{\circ} \mathrm{C}$ and completely burns out near $750^{\circ} \mathrm{C}$. The $5 \mathrm{wt} \%$ of residual catalyst was measured in this sample. Thus, it is calculated that the content of the CNTs in the product is about $95 \%$.

Figure 7(a) shows Raman spectra of the sample synthesized at $650^{\circ} \mathrm{C}-950^{\circ} \mathrm{C}$. In the high-frequency region, the Raman spectra have two characteristic peaks i.e. $\mathrm{G}$

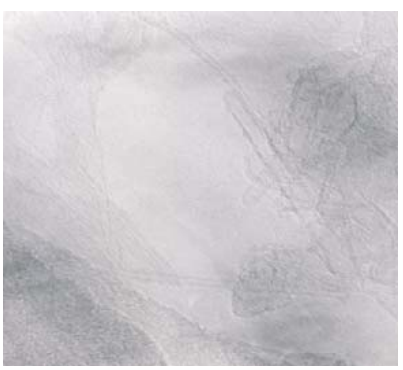

(a)

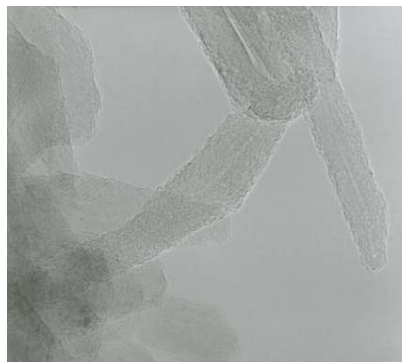

(c)

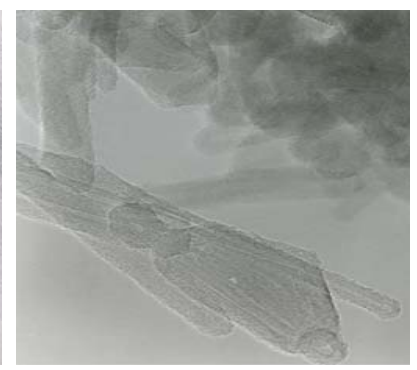

(b)

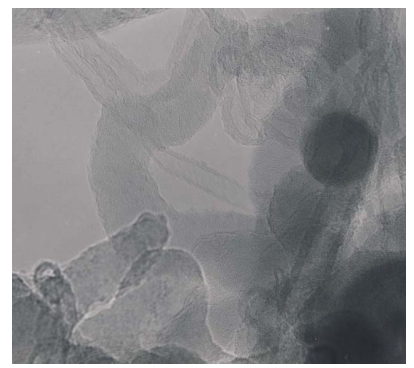

(d)
Figure 4. TEM images of CNTs on silicon substrate synthesized at: (a) $650^{\circ} \mathrm{C}$; (b) $750^{\circ} \mathrm{C}$; (c) $850^{\circ} \mathrm{C}$ and (d) $950^{\circ} \mathrm{C}$.

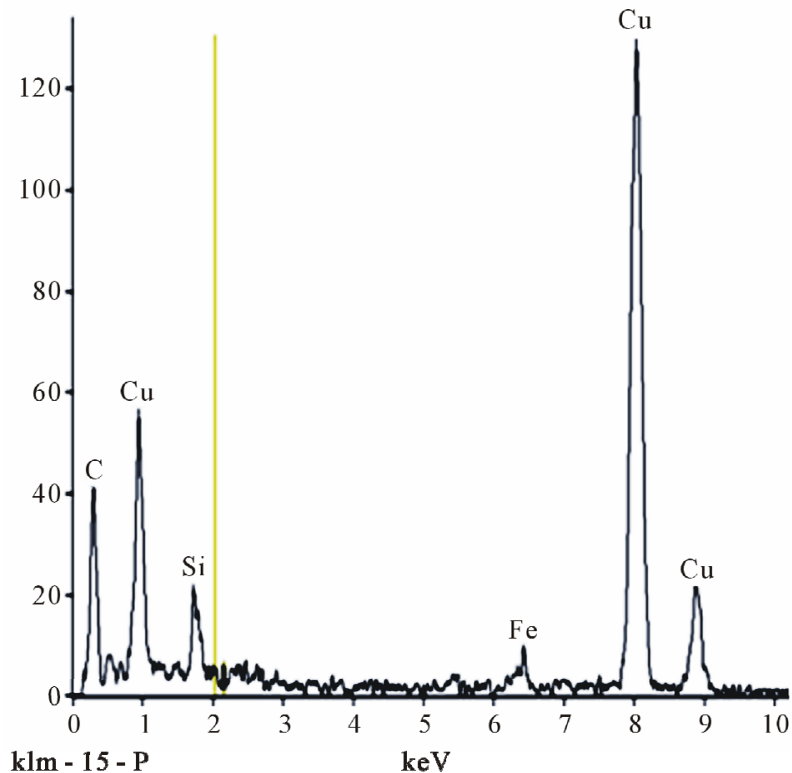

Figure 5. EDS curve of the VACNTs.

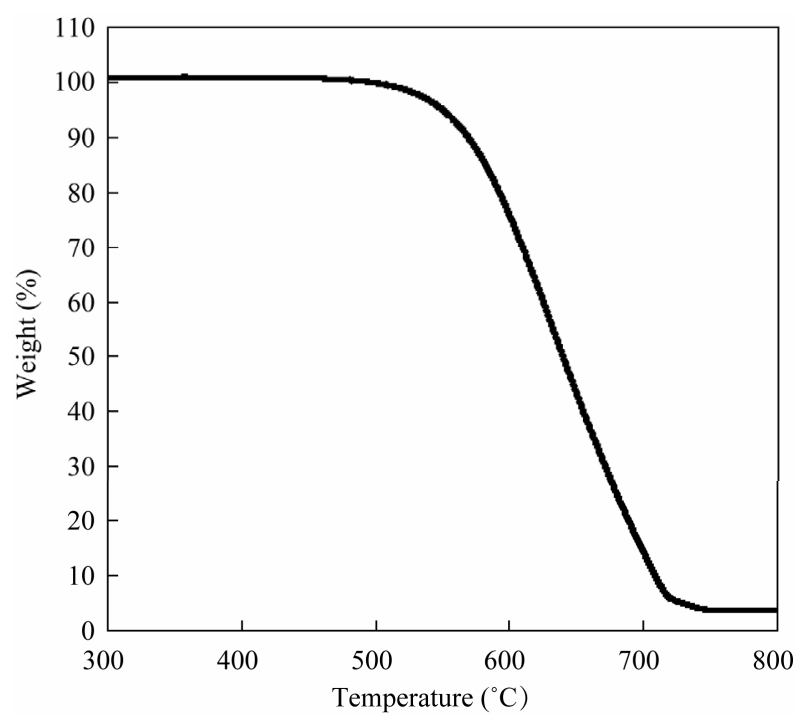

Figure 6. TGA curve of the VACNTs sample synthesized at $750^{\circ} \mathrm{C}$ substrate.

and D peaks. The D-peak observed around $1350 \mathrm{~cm}^{-1}$ relates to the presence of defects, while the G-peak around $1593 \mathrm{~cm}^{-1}$ is associated with the in-plane vibration of the graphene sheet. Ratios of the G-peak to the D-peak have been used as an indicator of the amount of disorder of the CNTs and graphite crystals [11]. The presence of high intensity of the G-peak provides the evidence of high graphitic order in CNTs. Both G peak and $\mathrm{D}$ peak are used to determine the structural quality of the CNTs. Higher the value of the $I_{G} / I_{D}$ corresponds to the higher graphitic structure of the CNTs obtained at $650^{\circ} \mathrm{C}, 750^{\circ} \mathrm{C}$ and $850^{\circ} \mathrm{C}$. However, the high intensity of the D-peak was presented and is higher than G-peak at 


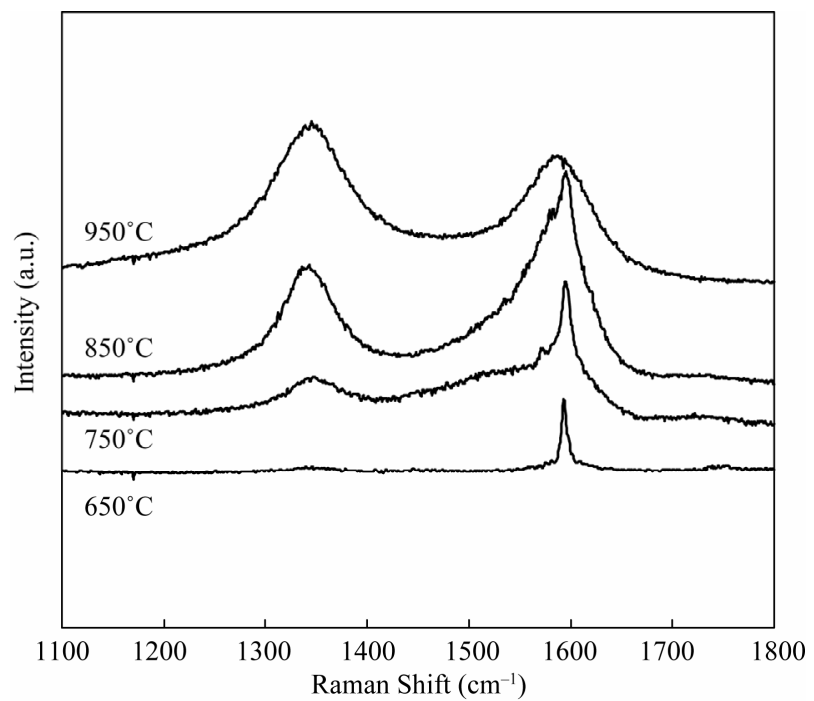

(a)

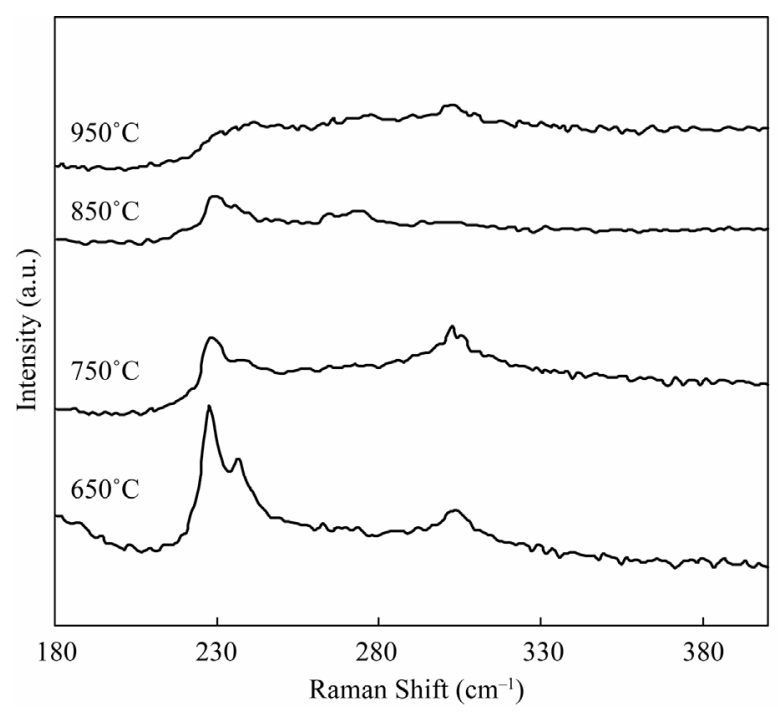

(b)

Figure 7. (a) Raman spectra of the samples synthesized at $650^{\circ} \mathrm{C}, 750^{\circ} \mathrm{C}, 850^{\circ} \mathrm{C}$ and $950^{\circ} \mathrm{C}$ in high frequency region; (b) Raman spectra of the samples synthesized at $650^{\circ} \mathrm{C}, 750^{\circ} \mathrm{C}$, $850^{\circ} \mathrm{C}$ and $950^{\circ} \mathrm{C}$ in low frequency region.

$950^{\circ} \mathrm{C}$, it explained that the plenty of amorphous carbon and defects existed at this temperature [12]. Figure 7(b) shows an expanded view of the low frequency region [13], in which radial breathing modes (RBMs) (180 - 400 $\mathrm{cm}^{-1}$ ) of SWNTs are observed for the samples synthesized at $650^{\circ} \mathrm{C}-850^{\circ} \mathrm{C}$, which suggested a threshold temperature somewhere between $650^{\circ} \mathrm{C}$ and $850^{\circ} \mathrm{C}$ for SWNTs synthesis under the chosen conditions.

The growth mechanism of VACNTs is still needs further study in the CVD method. The possible VACNTs mechanism in our study cannot be attributed to the growth of template but maybe to the steric of "crowding" [13]. Both Fe and ethanol source compounds are broken

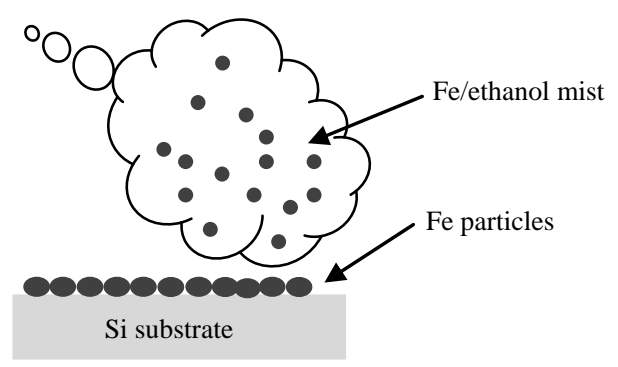

(a)

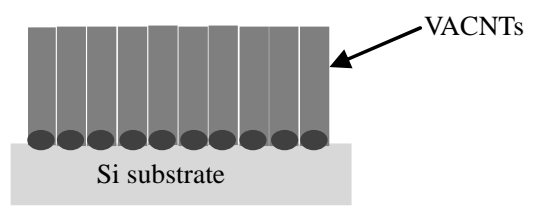

(b)

Figure 8. Schematic diagrams of growth mechanism of VACNT. (a) Formation of nano-size catalysts from $\mathrm{Fe}$ / ethanol mist; (b) The VACNTs were synthesized on the Si substrate.

down to form free Fe and carbon atoms. The Fe atoms can aggregate into small, nano-sized particles and sputter down to the Si substrate. The sputter deposition on the Si substrate will form some growth basis of VACNTs on the Si substrate. The diffusion of ethanol into these clusters begins to occur soon after the formation of the particles themselves. The carbon reaches to saturation point quickly. As the carbon source is supplied continually, the precipitation of graphite starts. The growth of the CNTs will be directed perpendicular to the Si substrate surface to form the densely packed, well-aligned mats observed. This process is illustrated schematically in Figures 8(a) and (b). We considered that interactions and "crowding" between CNTs is cause of the good VACNTs.

\section{REFERENCES}

[1] S. Iijima, "Helical Microtubules of Graphitic Carbon," Nature, Vol. 354, No. 6348, 1991, pp. 56-58. doi:10.1038/354056a0

[2] S. Yi, H. Zhang, L. Pei, S. Hu and L. Hu, "The Study of the Electrochemical Properties of CNTs-LaNi ${ }_{5}$ Electrodes," Materials Science and Engineering B, Vol. 128, No. 1-3, 2006, pp. 125-129.

doi:10.1016/j.mseb.2005.11.038

[3] M. Mann, Y. Zhang, K. B. K. Teo, T. Wells, M. M. El Gomati and W. I. Milne, "Controlling the Growth of Carbon Nanotubes for Electronic Devices,” Microelectronic Engineering, Vol. 87, No. 5-8, 2010, pp. 1491-1493. doi:10.1016/j.mee.2009.11.072

[4] S. C. Ray, U. Palnitkar, C. W. Pao, H. M. Tsai, W. F. Pong, I. N. Lin, P. Papakonstantinou, L. C. Chen and K. H. Chen, "Enhancement of Electron Field Emission of Nitrogenated Carbon Nanotubes on Chlorination,” Dia- 
mond and Related Materials, Vol. 18, No. 2-3, 2009, pp. 457-460. doi:10.1016/j.diamond.2008.07.016

[5] E. Titus, G. Cabral, J. C. Madaleno, V. F. Neto, T. Shokuhfar, W. J. Blau, P. R. Babu, D. S. Misra and J. Gracio, "Synthesis of Highly Oriented Carbon Nanotube Thin Films by Nickel Functionalisation,” Diamond and Related Materials, Vol. 16, No. 4-7, 2007, pp. 1195-1199. doi:10.1016/j.diamond.2006.11.033

[6] N. T. Hong, K. H. Koh, N. T. T. Tam, P. N. Minh, P. H. Khoi and S. Lee, "Combined Model for Growing Mechanism of Carbon Nanotubes Using HFCVD: Effect of Temperature and Molecule Gas Diffusion,” Thin Solid Films, Vol. 517, No. 12, 2009, pp. 3562-3565. doi:10.1016/j.tsf.2009.01.066

[7] W. I. Milne, K. B. K. Teo, M. Chhowalla, G. A. J. Amaratunga, S. B. Lee, D. G. Hasko, H. Ahmed, O. Groening, P. Legagneux, L. Gangloff, J. P. Schnell, G. Pirio, D. Pribat, M. Castignolles, A. Loiseau, V. Semet and V. T. Binh, "Electrical and Field Emission Investigation of Individual Carbon Nanotubes from Plasma Enhanced Chemical Vapour Deposition," Diamond and Related Materials, Vol. 12, No. 3-7, 2003, pp. 422-428.

[8] C. Chiu, T. Tsai, N. Tai and C. Lee, "Synthesis of Ultra Long Vertically Aligned Carbon Nanotubes Using the Rapid Heating and Cooling System in the Thermal Chemical Vapor Deposition Process," Surface and Coatings Technology, Vol. 200, No. 8, 2006, pp. 3215-3219. doi:10.1016/j.surfcoat.2005.07.016
[9] R. A. Afre, T. Soga, T. Jimbo, M. Kumar, Y. Ando, M. Sharon, P. R. Somani and M. Umno, "Carbon Nanotubes by Spray Pyrolysis of Turpentine Oil at Different Temperatures and Their Studies," Microporous and Mesoporous Materials, Vol. 96, No. 1-3, 2006, pp. 184-190. doi:10.1016/j.micromeso.2006.06.036

[10] R. A. Afre, T. Soga, T. Jimbo, M. Kumar, Y. Ando and M. Sharon, "Growth of Vertically Aligned Carbon Nanotubes on Silicon and Quartz Substrate by Spray Pyrolysis of a Natural Precursor: Turpentine Oil,” Chemical Physics Letters, Vol. 414, No. 1-3, 2005, pp. 6-10. doi:10.1016/j.cplett.2005.08.040

[11] P. H. Tan, S. L. Zhang, K. T. Yue, F. M. Huang, Z. J. Shi, X. H. Zhou and Z. N. Gu, "Comparative Raman Study of Carbon Nanotubes Prepared by D.C. Arc Discharge and Catalytic Methods,” Journal of Raman Spectroscopy, Vol. 28, No. 5, 1997, pp. 369-372. doi:10.1002/(SICI)1097-4555(199705)28:5<369::AID-JR $\underline{\mathrm{S} 107>3.0 . \mathrm{CO} ; 2-\mathrm{X}}$

[12] M. S. Dresselhaus, G. Dresselhaus, A. Jorio, A. G. S. Filho and R. Saito, "Raman Spectroscopy on Isolated Single Wall Carbon Nanotubes,” Carbon, Vol. 40, No. 12, 2002, pp. 2043-2061. doi:10.1016/S0008-6223(02)00066-0

[13] P. J. Cao, Y. S. Gu, H. W. Liu, F. Shen, Y. G. Wang, Q. F. Zhang, J. L. Wu and H. J. Gao, "High Density Aligned Carbon Nanotubes with Uniform Diameters,” Journal of Materials Research, Vol. 18, No. 7, 2003, pp. 7-14. doi:10.1557/JMR.2003.0231 